FORCES IN DOUBLER TYPE SHEET CURRENT DIPOLES

\author{
S.C. Snowdon
}

March 22, 1974

Summary

The force distribution on a current sheet that simulates the current density distribution in the energy doubler dipole is calculated. For a perfectly centered dipole the magnetic forces result in a compressive force vertically and an elongative force horizontally. Net forces and torques on displaced current distribution are also calculated. Results are given for the dual test dipole, the doubler dipole, and the muon beam line dipole.

\title{
Magnetic Field
}

In complex variable notation, the magnetic field is given by

$$
\begin{array}{rl}
H^{*}=-2 i i_{0} & a \int_{-\frac{\pi}{2}}^{\frac{\pi}{2}}\left[\frac{1}{z-\delta-\Delta-a e^{i \theta}}+\frac{1}{z-\frac{b^{2}}{\delta^{*}+\Delta+a e^{-i \theta}}}\right] \cos \theta d \theta \\
-2 i i_{0} & a \int_{\frac{\pi}{2}}^{\frac{\pi}{2}}\left[\frac{1}{z-\delta+\Delta-a e^{i \theta}}+\frac{1}{z-\frac{b^{2}}{\delta^{*}-\Delta+a e^{-i \theta}}}\right] \cos \theta d \theta
\end{array}
$$

where it is assumed that the sheet current density is $i_{0} \cos \theta$. Figure 1 should be consulted for geometrical quantities. If one designates $s=e^{i \theta}$ then 


$$
\begin{aligned}
H^{*}= & -i_{0} a \int_{C_{1}}\left[\frac{1}{z-\delta-\Delta-a s}+\frac{a+\left(\delta^{*}+\Delta\right) s}{a z-\left[b^{2}-\left(\delta^{*}+\Delta\right) z\right]}\right]\left(1+\frac{1}{s^{2}}\right) d s \\
& -i_{0} a \int_{C_{2}}\left[\frac{1}{z-\delta+\Delta-a s}+\frac{a+\left(\delta^{*}-\Delta\right) s}{a z-\left[b^{2}-\left(\delta^{*}-\Delta\right) z\right]}\right]\left(1+\frac{1}{s^{2}}\right) d s .
\end{aligned}
$$

Integration gives

$$
\begin{aligned}
& H^{*}=-i\left\{-2 \pi i-\ln \left(\frac{i a-z+\delta+\Delta}{i a+z-\delta-\Delta} \cdot \frac{i a+z-\delta+\Delta}{i a-z+\delta-\Delta}\right)\right. \\
& -\frac{a}{z-\delta-\Delta}\left[-2 i+\frac{a}{z-\delta-\Delta} \ln \left(\frac{i a-z+\delta+\Delta}{i a+z-\delta-\Delta}\right)\right] \\
& -\frac{a}{z-\delta+\Delta}\left[2 i+\frac{a}{z-\delta+\Delta} \ln \left(\frac{i a+z-\delta+\Delta}{i a-z+\delta-\Delta}\right)\right] \\
& -\frac{2 i a\left(\delta^{*}+\Delta\right)}{b^{2}-\left(\delta^{*}+\Delta\right) z}+\frac{2 i a\left(\delta^{*}-\Delta\right)}{b^{2}-\left(\delta^{*}-\Delta\right) z} \\
& -\frac{a^{2} b^{2}}{\left[b^{2}-\left(\delta^{*}+\Delta\right) z\right]^{2}}\left[i \pi+\ln \left(\frac{i\left[b^{2}-\left(\delta^{*}+\Delta\right) z\right]-a z}{i\left[b^{2}-\left(\delta^{*}+\Delta\right) z\right]+a z}\right)\right] \\
& -\frac{a^{2} b^{2}}{\left[b^{2}-\left(\delta^{*}-\Delta\right) z\right]^{2}}\left[i \pi+\ln \left(\frac{i\left[b^{2}-\left(\delta^{*}-\Delta\right) z\right]+a z}{i\left[b^{2}-\left(\delta^{*}-\Delta\right) z\right]-a z}\right)\right] \\
& \left.-\frac{b^{2}}{z^{2}} \cdot \ln \left(\frac{i\left[b^{2}-\left(\delta^{*}+\Delta\right) z\right]-a z}{i\left[b^{2}-\left(\delta^{*}+\Delta\right) z\right]+a z}+\frac{i\left[b^{2}-\left(\delta^{*}-\Delta\right) z\right]+a z}{i\left[b^{2}-\left(\delta^{*}-\Delta\right) z\right]-a z}\right)\right\}
\end{aligned}
$$


where the arguments of the logarithmic terms have been arranged so that the solution is appropriate to the inside region.

For $z$ on the current sheet the field is discontinuous such that

$$
\mathrm{H}_{t}^{+}-\mathrm{H}_{t}^{-}=4 \pi i_{0} \cos \theta \quad, \quad \mathrm{H}_{\mathrm{n}}^{+}=\mathrm{H}_{\mathrm{n}}^{-}
$$

which yields

$$
H^{*}(+)-H^{*}(-)=-4 \pi i i_{0} \cos \theta e^{-i \theta} \text {. }
$$

Hence the average field in the current sheet is

$$
\left\langle\mathrm{H}^{*}\right\rangle_{\mathrm{AV}}=\mathrm{H}^{*}(-)-i \pi i_{0}\left(1+\mathrm{e}^{-2 i \theta}\right) \text {. }
$$

Force

If $\mathrm{S}_{\mathrm{x}}$ and $\mathrm{S}_{\mathrm{y}}$ designate stresses on a unit area of the current sheet, then

$$
S^{*}=S_{x}-i S_{y}=-i<H^{*}>_{A v} i_{0} \cos \theta
$$

The net force per unit length of current sheet is then

$$
F^{*}=\oint_{C} S^{*} \text { ad } \theta \text {. }
$$

\section{Torque}

The torque per unit length of the current sheet is

$$
T_{z}=\operatorname{Real}\left[i \oint_{c} z S^{*} \operatorname{ad} \theta\right] \text {. }
$$

There can be no torque about the central axis since the iron shield in symmetrical about this axis. However, if $z=\delta+z^{\prime}$, the origin of $z^{\prime}$ being center of the displaced bore tube then, 


$$
T_{z^{\prime}}=\operatorname{ReaI}\left[i \oint_{\mathrm{C}} z^{\prime} S^{*} \operatorname{ad} \theta\right] \text {. }
$$

But

$$
\mathrm{T}_{\mathrm{z}}=0=\operatorname{Real}\left[i \oint_{\mathrm{C}}\left(\delta+\mathrm{z}^{\prime}\right) \mathrm{S}^{*} \mathrm{ad} \theta\right] \text {. }
$$

Hence

$$
\mathrm{T}_{\mathrm{z}^{\prime}}=-\operatorname{Real}\left[i \delta \oint_{\mathrm{C}} \mathrm{S}^{*} \operatorname{ad} \theta\right]=-\operatorname{Real}\left(i \delta \mathrm{F}^{*}\right)
$$

\section{Results}

Application of the previous formulas using input data appropriate for the dual test dipole, the doubler dipole, and the muon beam line dipole gives the results shown in Tables (1-3). 


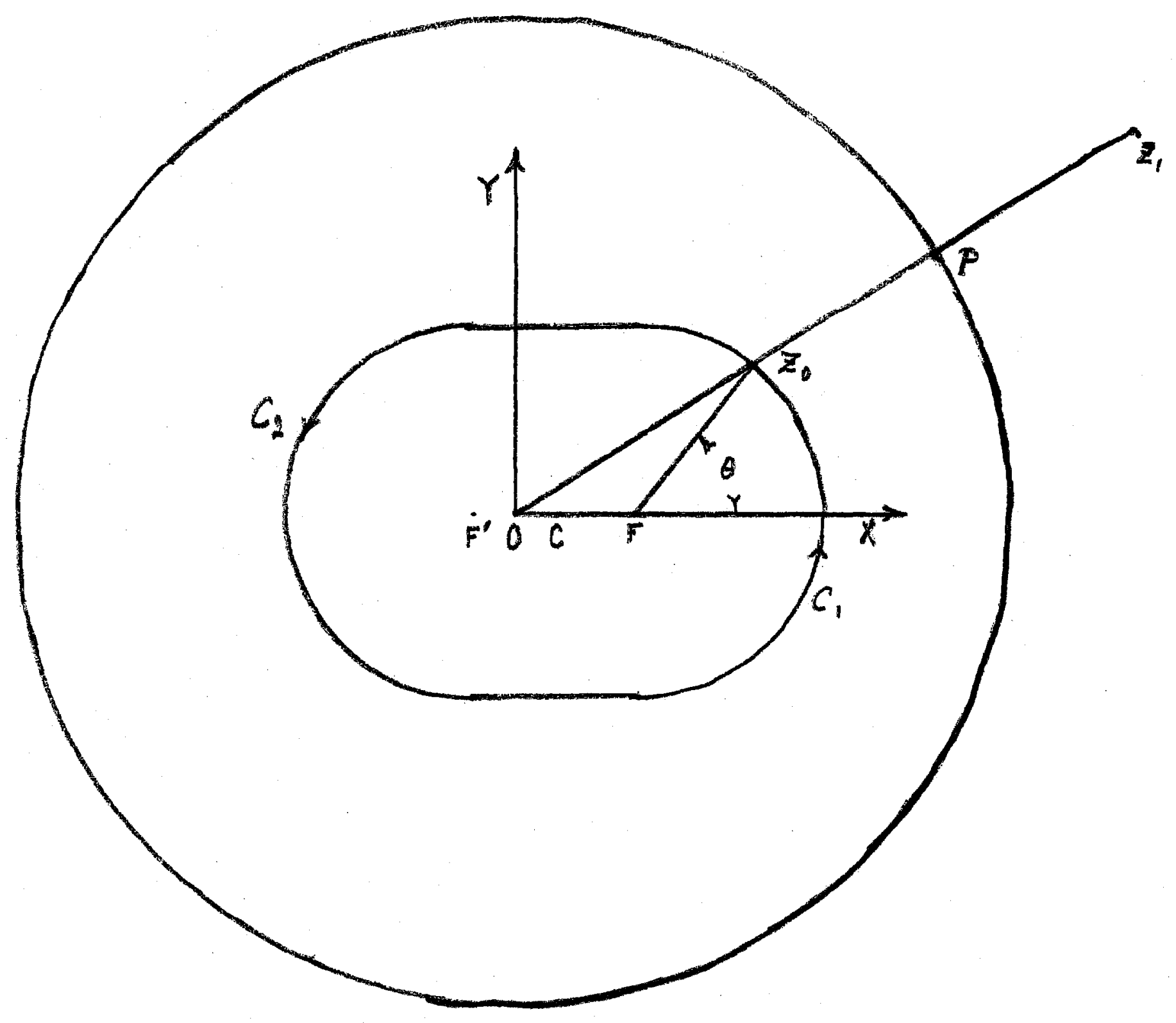

Figure 1. Sheet Current Dipole (See Legend) 


\section{Figure 1. Legend}

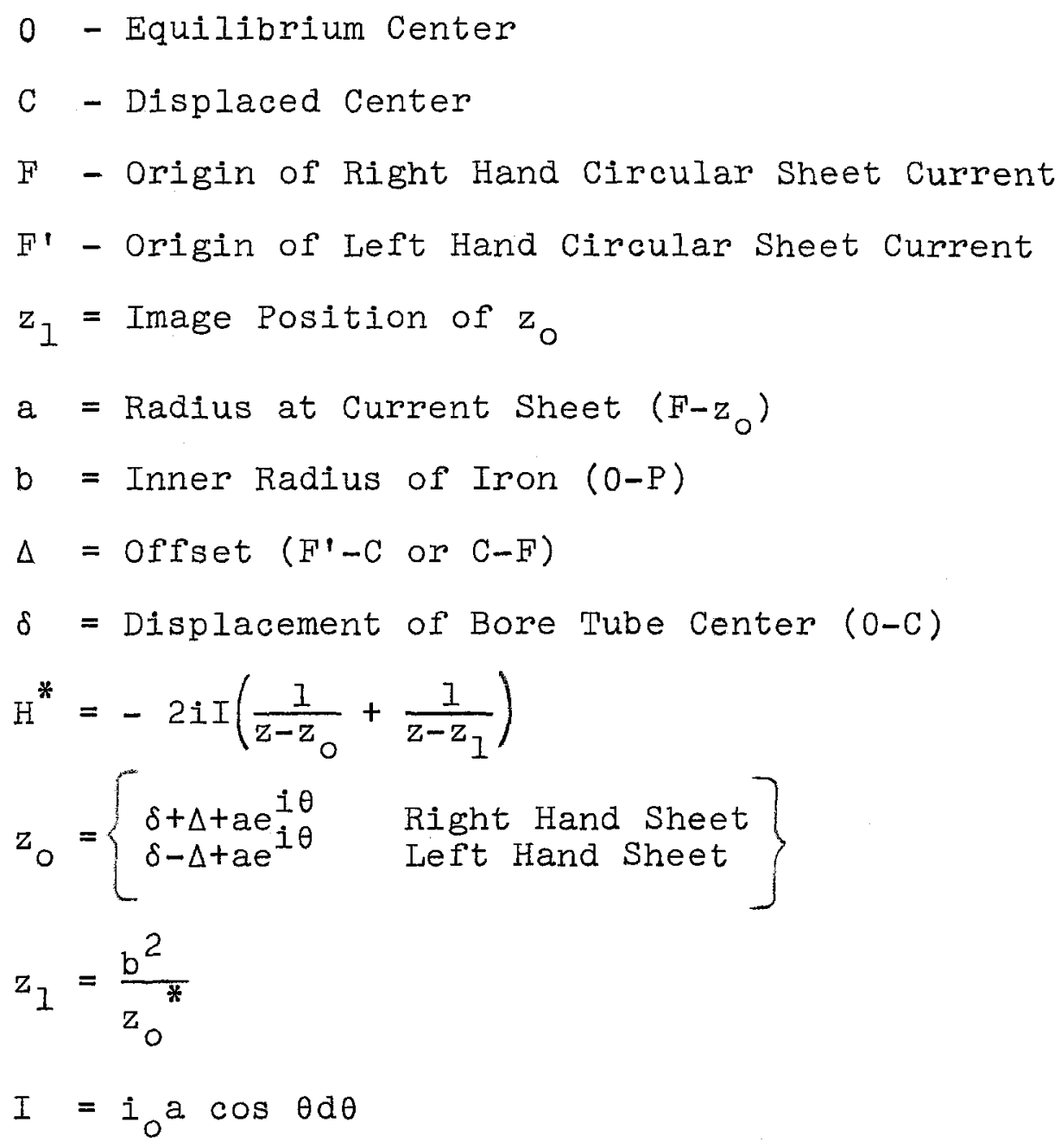


Table 1. Magnetic Stresses in Dual Test Dipole

Conductor Current

Number of Conductors

Current Sheet Radius

Current Sheet offset

Inner Radius of Iron

Central Field

Stress:

\section{Angle \\ (Deg)}

1

0

10

20

30

40

50

60

70

80

90

2

90
2625A

130

1. $340 \mathrm{in}$

.000 in

$3.050 \mathrm{in}$

$37.6 \mathrm{kG}$

100

110

120

130

140

150

160

170

180

X-Stress
$(P / i n / i n)$
441
503
666
877
1062
1146
1078
842
462
0
0
-462
-842
-1078
-1146
-1062
-877
-666
-503
-441

Y-Stress

(P/in/in)

0

$-385$

$-691$

$-858$

$-863$

$-724$

$-495$

$-251$

$-68$

0 .

0

$-68$

$-251$

$-495$

$-724$

$-863$

$-858$

$-691$

$-385$ 


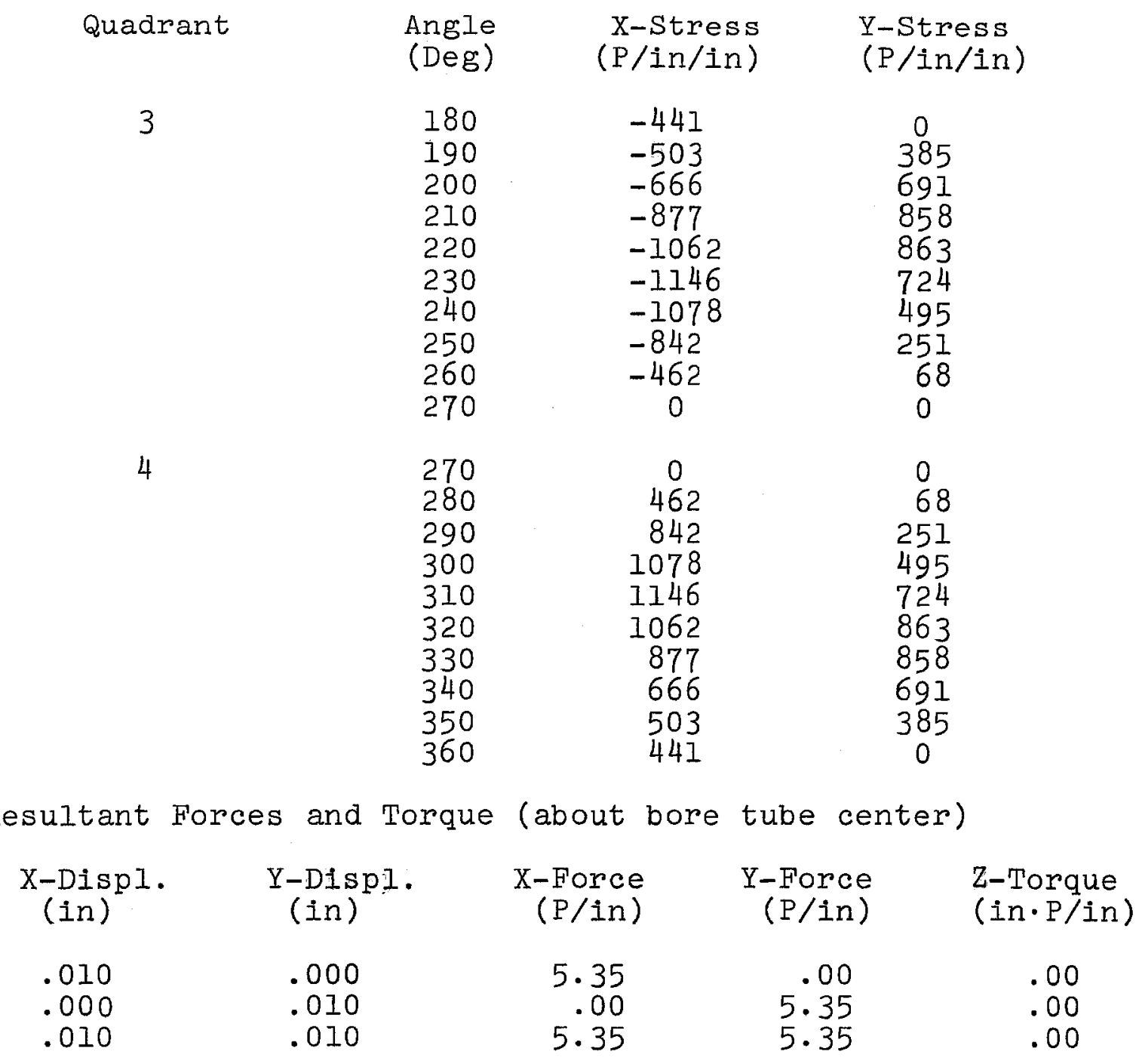

Resultant Forces and Torque (about bore tube center) 
Table 2. Magnetic Stresses in Doubler Dipole

Conductor Current

Number of Conductors

Current Sheet Radius

Current Sheet offset

Inner Radius of Iron

Central Field

Stress:

Quadrant

2

90
100
110
120
130
140
150
160
170
180

1

10

20

30

40

50

60

70

80

90

Angle

Deg)

0

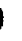

0

0

.

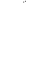

$2815 \mathrm{~A}$

140

1.1325 in

.375 in

3.0625 in

$45.5 \mathrm{kG}$ 
Table 2. (Cont.)

Quadrant

3

4

$$
\begin{aligned}
& \text { Angle } \\
& \text { (Deg) }
\end{aligned}
$$

180

190

200

210

220

230

240

250

260

270

270

280

290

300

310

320

330

340

350

360

\section{X-Stress \\ (P/in/in)}

$-534$

$-651$

$-1374$

$-1740$

$-1925$

$-1832$

$-1431$

$-775$

0

0
775
1431
1832
1925
1740
1374
965
651
534

Y-Stress

( $\mathrm{P} /$ in/in)

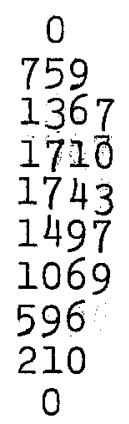

0

210

596

1069

1497

1743

1710

1367

759

Resultant Force and Torque (about bore tube center)

$\begin{array}{ccccc}\begin{array}{c}\text { X-Displ. } \\ (\text { in })\end{array} & \begin{array}{c}\text { Y-Discpl. } \\ \text { (in) }\end{array} & \begin{array}{c}\text { X-Force } \\ \text { (P/in) }\end{array} & \begin{array}{c}\text { Y-Force } \\ (\text { P/in) }\end{array} & \begin{array}{c}\text { Z-Torque } \\ (\text { in.P/in) }\end{array} \\ .010 & .000 & 11.04 & .00 & .00 \\ .000 & .010 & .00 & 9.48 & .00 \\ .010 & .010 & 11.04 & 9.48 & .0156\end{array}$


Table 3. Magnetic Stresses in Muon Line Dipole

Conductor Current

Number of Conductors

Current sheet Radius

Current Sheet Offset

Inner Radius of Iron

Central Field

Stress :
$2380 \mathrm{~A}$

306

2.489 in

$1.000 \mathrm{in}$

5.750 in

$40.5 \mathrm{kG}$

Quadrant

Angle

X-Stress

Y-Stress

(Deg)

(P/in/in)

( $P /$ in/in)

1

0

10

20

30

40

50

60

70

80

90

2

90

100

110

120

130

140

150

160

170

180

0

$-548$

$-988$

$-1237$

$-1264$

$-1089$

$-782$

$-440$

$-160$

585

$$
0
$$

0

$-585$

$-1088$

$-1410$

$-1514$

$-1419$

$-1191$

$-926$

$-719$

$-642$

$$
\begin{gathered}
0 \\
-160 \\
-440 \\
-782 \\
-1089 \\
-1264 \\
-1237 \\
-988 \\
-548 \\
0
\end{gathered}
$$




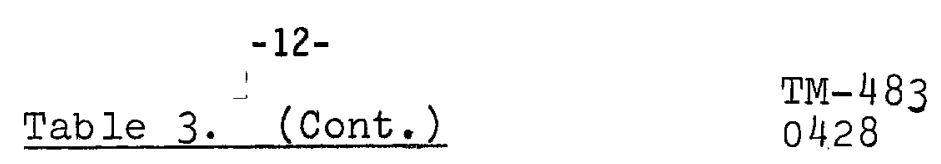

\begin{tabular}{|c|c|c|c|}
\hline Quadrant & $\begin{array}{l}\text { Angle } \\
\text { (Deg) }\end{array}$ & $\begin{array}{r}\text { X-Stress } \\
(P / \text { in/in })\end{array}$ & $\begin{array}{l}\text { Y-Stress } \\
(P / \text { in/in })\end{array}$ \\
\hline 3 & $\begin{array}{l}180 \\
190 \\
200 \\
210 \\
220 \\
230 \\
240 \\
250 \\
260 \\
270\end{array}$ & $\begin{array}{c}-642 \\
-719 \\
-926 \\
-1191 \\
-1419 \\
-1514 \\
-1410 \\
-1088 \\
-585 \\
0\end{array}$ & $\begin{array}{c}0 \\
548 \\
988 \\
1237 \\
1264 \\
1089 \\
782 \\
440 \\
160 \\
0\end{array}$ \\
\hline 4 & $\begin{array}{l}270 \\
280 \\
290 \\
300 \\
310 \\
320 \\
330 \\
340 \\
350 \\
360\end{array}$ & $\begin{array}{r}0 \\
585 \\
1088 \\
1410 \\
1514 \\
1419 \\
1191 \\
926 \\
719 \\
642\end{array}$ & $\begin{array}{c}0 \\
160 \\
440 \\
782 \\
1089 \\
1264 \\
1237 \\
988 \\
548 \\
0\end{array}$ \\
\hline
\end{tabular}

Resultant Force and Torque (about bore tube center)

$\begin{array}{ccccc}\begin{array}{c}\text { X-Displ. } \\ (\text { in })\end{array} & \begin{array}{c}\text { Y-Displ. } \\ (\text { in })\end{array} & \begin{array}{c}\text { X-Force } \\ (\mathrm{P} / \text { in) }\end{array} & \begin{array}{c}\text { Y-Force } \\ (\mathrm{P} / \text { in })\end{array} & \begin{array}{c}\text { Z-Torque } \\ (\text { in.P/in) }\end{array} \\ .010 & .000 & 17.82 & .00 & .00 \\ .000 & .010 & .00 & 13.70 & .00 \\ .010 & .010 & 17.82 & 13.70 & .0412\end{array}$

